\title{
DINAR DIRHAM SEBAGAI ALTERNATIF INVESTASI DAN HEDGING YANG AMAN
}

\author{
Finda Findiana \\ STEBI Global Mulia Cikarang \\ Email: findafindiana@gmail.com
}

\begin{abstract}
The inflation rate which tends to increase in the decade has made the price of goods getting more expensive in the society. The expensive price of goods have results in increasingly heavy burdens that must be burden by the society, make poverty everywhere, make a lot of unemployee. The society must be looking for another job to cover their living needs by investing in some of their assets, there are also some people who have middle and upper class, of course they are not only thinking about investing but also how to protect their assets from the negative effects of inflation that is by doing hedging (hedging). One instrument of investment and hedging is to save Dinars and Dirhams. The desire to invest or hedge in foreign currencies namely Dinar and Dirham must be supported by many parties because investing and hedging with Dinar and Dirham can make economic nation going strength for the people and the nation.
\end{abstract}

Keywords: Dinar, Dirhams, Investation, Hedging.

Abstrak: Tingkat inflasi yang cenderung selalu bertambah dalam kurun waktu sepuluh tahun ini, telah membuat semakin tingginya harga barang-barang dalam masyarakat. Tingginya harga barang mengakibatkan semakin beratnya beban yang harus ditanggung masyarakat, kemiskinan semakin meluas, pengangguran semakin banyak. Masyarakat dituntut untuk mencari sumber penghasilan lain untuk menutup kebutuhan hidupnya dengan cara melakukan investasi atas sebagian hartanya, ada juga sebagian masyarakat yang memiliki ekonomi yang menengah dan atas, tentu mereka tidak hanya berfikir tentang berinvestasi tapi juga bagaimana bisa melindungi nilai hartanya dari efek negatif dari inflasi yaitu dengan melakukan hedging (lindung nilai). Salah satu instrument dari investasi dan hedging adalah dengan menyimpan Dinar dan Dirham. Keinginan berinvestasi atau melakukan 
hedging dalam mata uang asing yaitu Dinar dan Dirham harus didukung oleh banyak pihak karena dengan berinvestasi dan ber-hedging dengan Dinar dan Dirham bisa membawa kepada semakin kokohnya ekonomi rakyat dan bangsa.

Kata Kunci: Dinar, Dirham, Investasi, Hedging. 


\section{Pendahuluan}

Tingkat inflasi yang selalu ada setiap bulannya mendorong masyarakat Indonesia semakin ulet dalam mencari tambahan penghasilan setiap bulan agar terpenuhi segala kebutuhan dalam rumah tangga masyarakat Indonesia, sedangkan di lapisan masyarakat menengah keatas yang sadar akan tingkat inflasi ini melakukan usaha untuk menyelamatkan nilai simpanan harta pribadi agar tidak tergerus oleh nilai tukar rupiah yang tidak kunjung menguat atas nilai dollar Amerika.

Banyak cara yang dilakukan oleh masyarakat untuk mendapatkan pendapatan tambahan ataupun meningkatkan nilai simpanan harta pribadi, antara lain dengan melakukan investasi, baik itu investasi di sektor riil maupun investasi di sektor non riil misalnya dengan melakukan investasi di pasar modal.

Sebagian besar masyarakat Indonesia yang merupakan umat muslim, tentu dalam melakukan investasi seharusnya berpedoman pada investasi yang sesuai dengan prinsip-prinsip syariah. Artinya investasi yang sesuai dengan ketentuan dan tuntunan ajaran agama islam. Adapun tujuan dari investasi yang sesuai syariah ini adalah agar tercapai tujuan umat muslim dalam melakukan kegiatan ekonomi yang syariah. Tujuan kegiatan ekonomi syariah adalah untuk mencapai kebahagiaan yang bersifat falah artinya tercapainya kebahagiaan dunia dan akhirat.

Investasi yang baik adalah investasi yang bisa memberikan tingkat keuntungan yang tinggi, Semakin tinggi tingkat keuntungan investasi, umumnya juga berpotensi memberikan tingkat kerugian yang tinggi juga. Investasi yang paling menguntungkan adalah investasi yang mengalahkan inflasi. ${ }^{1}$

\footnotetext{
1 Bareyn Mochaddin, 3 Investasi yang Paling Menguntungkan Mana Pilihan Anda. dikutip dari https://finance.detik.com/perencanaan-keuangan/d-3346340 diakses 22 Oktober 2018
} 


\section{Pengertian Inflasi}

Pada awalnya inflasi diartikan sebagai kenaikan jumlah uang beredar atau kenaikan likuiditas dalam suatu perekonomian. Pengertian tersebut mengacu pada gejala umum yang ditimbulkan oleh adanya kenaikan jumlah uang beredar yang diduga telah menyebabkan adanya kenaikan harga-harga. Dalam perkembangan lebih lanjut, inflasi secara singkat dapat diartikan sebagai suatu kecenderungan meningkatnya harga-harga barang dan jasa secara umum dan terus-menerus. ${ }^{2}$

Inflasi, kenaikan harga barang dan jasa secara umum, yang tinggi akan menjadi beban oleh banyak pihak. Dengan inflasi, maka daya beli suatu mata uang menjadi lebih rendah atau menurun. Dengan menurunnya daya beli mata uang, maka kemampuan masyarakat berpendapatan tetap dalam membeli barang dan jasa kebutuhan sehari-hari akan menjadi semakin rendah. Laju inflasi yang tidak stabil juga menyulitkan perencanaan bagi dunia usaha, tidak mendorong masyarakat untuk menabung, dan berbagai dampak negatif lain yang tidak kondusif bagi perekonomian secara keseluruhan. $^{3}$

Dengan adanya inflasi inilah masyarakat diharapkan untuk melakukan upaya penyelamatan akan kemampuan daya belinya dengan berbagai macam cara yang sesuai dengan syariah, antara lain dengan investasi ataupun dengan cara lindung nilai (hedging).

\section{Sejarah Perjalanan Melemahnya Mata Uang Rupiah terhadap Dollar}

Inflasi yang disebabkan oleh melemahnya nilai tukar rupiah terhadap dollar tidak luput dari sejarah panjang perjalanan ekonomi moneter dunia. Pada zaman dahulu, Dinar dan dirham adalah alat tukar perdagangan yang telah dikenal ribuan tahun yang lalu seperti dalam

\footnotetext{
2 Suseno, Siti Astiyah, Inflasi. (Jakarta: Pusat Pendidikan dan Studi Kebanksentralan (PPSK) Bank Indonesia, 2009) cet. ke-1, h. iv - 2

${ }^{3}$ Ibid
}

KORDINAT Vol. XVIII No. 1 April 2019 
sejarah Mesir kuno sekitar 4000 - 2000 SM. Dalam bentuknya yang lebih standar uang emas dan perak diperkenalkan oleh Julius Caesar dari Romawi sekitar tahun 46 SM. Julius Caesar ini pula yang memperkenalkan standar konversi dari uang emas ke uang perak dan sebaliknya dengan perbandingan 12:1 untuk perak terhadap emas. Standar Julius Caesar ini berlaku di belahan dunia Eropa selama sekitar 1250 tahun yaitu sampai tahun $1204 .^{4}$

Menurut Muhaimin Iqbal (dalam Surahman) di dunia Islam, uang emas dan perak yang dikenal dengan dinar dan dirham juga digunakan sejak awal Islam baik untuk kegiatan muamalah maupun ibadah seperti zakat dan diyat sampai berakhirnya kekhilafahan Usmaniyah Turki pada tahun 1924. Berat 1 dinar ini sama dengan 1 mitsqal atau setara dengan berat 72 butir gandum ukuran sedang yang dipotong kedua ujungnya. Dari dinar- dinar yang tersimpan di museum setelah ditmbang dengan timbangan yang akurat diketahui bahwa timbangan berat uang 1 dinar Islam yang diterbitkan pada masa Khalifah Abdul Malik bin Marwan adalah 4,25 gram. Berat ini sama dengan berat mata uang Byzantium yang disebut Solidos dan mata uang Yunani yang disebut Drachma. ${ }^{5}$

Penggunaan standar emas memiliki tiga masa, yaitu masa standar emas klasik "classical gold standart" sekitar tahun 1770 - 1914, masa standar tukar emas sekitar tahun 1925 - 1930, masa sistem Bretton Wood yang dimulai tahun $1946-1971 .^{6}$

Berakhirnya sistem standar emas klasik atau lebih dikenal dengan "Classical gold standard" yang terus diikuti dengan diakhirinya sistem pengganti yang mirip dengannya, yaitu sistem Bretton Wood pada awal tahun 1971, menandai era baru sistem moneter internasional dibawah sistem kurs mengambang (flexible exchang rate). Sejak tahun 1971 tersebut praktis seluruh otoritas moneter dunia menggunakan kembali

\footnotetext{
${ }^{4}$ Muhaimin Iqbal, Mengembalikan Kemakmuran Islam dengan Dinar dan Dirham, (Jakarta: Spiritual Learning Centre - Dinar Club, 2007) cet. ke-1, h. 18.

${ }^{5}$ Surahman, Analisis Kekuatan Dinar dan Dirham Sebagai Mata Uang Anti Krisis, (Banten: Jurnal Ekonomi dan Bisnis Islam IAIN Sultan Maulana Hasanuddin, vol.1 no.2, 2016) cet ke-1, h. 126.

${ }^{6}$ M. Nur Rianto Al Arif, Pengantar Ekonomi Syariah, (Bandung: Pustaka Setia, 2015) cet ke-1. h. 302.
} 
uang fiat murni yaitu uang yang tidak didukung oleh adanya cadangan emas. $^{7}$

Sejak pencetakan uang kertas tidak didukung dengan emas terlihat berbagai fenomena dalam sistem keuangan global. Berbagai krisis yang terjadi menunjukkan tanda tanda keruntuhan ekonomi, keputusan negaranegara melepaskan jaminan penopang uang kertas dengan emas secara total mengakibatkan setiap negara bebas untuk mencetak uang berapapun yang dikehendaki sesuai dengan keperluan tanpa syarat yang mengontrol proses penerbitan. Akibatnya, muncul kekurangan dari penggunaan uang kertas tersebut. ${ }^{8}$

Dampak kebijakan moneter dalam penggunaan dollar sebagai patokan standar menggantikan standar emas, telah menimbulkan banyaknya permintaan akan dollar. Bank Sentral Amerika mencetak banyak uang dollar untuk memenuhi kebutuhan dunia akan dollar dan menyebarkannya kepada seluruh dunia. Semakin banyak permintaan akan dollar, maka harga dollar semakin tinggi. Di Indonesia sendiri kebutuhan akan dollar juga sangat tinggi dan mendorong nilai harga dollar menjadi semakin tinggi, sehingga Bank Indonesia harus mencetak lebih banyak lagi uang Rupiah untuk dapat membeli dollar.

Banyaknya jumlah uang yang dicetak dan beredar mengakibatkan adanya peningkatkan pada harga dan nilai uang menjadi turun. Teori yang mendukung penjelasan ini disebut teori jumlah uang (quantity theory of money). Menurut teori ini, jumlah uang yang tersedia dalam perekonomian menentukan nilai uang, dan pertumbuhan jumlah uang adalah penyebab utama inflasi. Seperti dikatakan oleh ekonom dari Amerika, Milton Friedman, "inflasi selalu dan dimana pun menjadi sebuah fenomena moneter".

\footnotetext{
${ }^{7}$ Ibid, Muhaimin Iqbal, h. 26.

${ }^{8}$ Ibid, M. Nur Rianto Al Arif, h. 304

${ }^{9}$ N. Gregory Mankiw, Euston Quah, Peter Wilson, Pengantar Ekonomi Makro Edisi Asia, (Jakarta:Salemba Empat, 2013) cet. Ke-1. h. 159.
} 


\section{Pengertian Lindung Nilai (Hedging)}

Lindung nilai berasal dari kata serapan hedge. Dalam dunia keuangan, lindung nilai diartikan suatu investasi yang dilakukan untuk mengurangi ataupun meniadakan risiko pada suatu investasi lain yang dilakukan para pelaku bisnis. Lindung nilai adalah suatu strategi yang dilakukan untuk mengurangi terjadinya risiko bisnis yang tidak terduga, di samping tetap dimungkinkannya memperoleh keuntungan. ${ }^{10}$

Menurut Setiawan Budi Utomo dalam (Oni Sahroni, Hasanuddin, Cecep Maskanul Hakim) Lindung nilai (Hedging/al-Tahawuth) adalah cara atau teknik untuk mengurangi risiko yang timbul maupun yang diperkirakan akan timbul akibat adanya fluktuasi harga di pasar keuangan. ${ }^{11}$

Dalam dunia perbankan, secara sederhana, hedging dilakukan dengan cara mematok harga valuta pada kurs tertentu untuk mengantisipasi kerugian akibat naik atau turunnya nilai valuta asing tersebut dengan cara forward atau swap atau option. Bisnis itu bisa menghasilkan keuntungan besar, tetapi bisa menjadi merugi karena nilai tukarnya rendah. ${ }^{12}$

Tindakan lindung nilai ini tidak hanya dilakukan oleh sector perbankan, tapi juga bisa dilakukan oleh perusahaan ataupun perseorangan dalam rangka mengantisipasi adanya kerugian karena perubahan selisih kurs rupiah terhadap mata uang asing yang memiliki imbas pada kemampuan daya beli yang menurun.

Bagi masyarakat yang memiliki kekayaan dalam bentuk uang tunai Rupiah bisa melakukan tindakan hedging agar nilai kekayaannya tidak menurun karena adanya perubahan nilai tukar kurs Rupiah terhadap Dollar yaitu dengan merubah kekayaan tunainya menjadi Dinar dan Dirham yang bisa disimpan, memiliki nilai yang stabil dan anti inflasi. Apabila suatu saat nanti dimasa depan mereka

\footnotetext{
10 Ridho Cahyo Nugroho, Konsep Lindung Nilai (hedging) dalam Transaksi Keuangan Syariah (Malang:FEB Unbraw, 2016). cet. ke-1, h. 3.

${ }^{11}$ Oni Sahroni, Hasanuddin, Cecep Maskanul Hakim, Instrumen Hedging dan Solusinya Menurut Syariah (Bengkulu:Jurnal Ekonomi dan Perbankan Syariah Al Intaj vol. 2 no. 2 FEBI IAIN Bengkulu, 2016). cet ke1. h. 71

${ }^{12} \mathrm{Ibid}$
} 
membutuhkan uang tunai, masyarakat bisa menukarkan Dinar dan Dirhamnya ke dalam Rupiah yang pastinya memiliki nilai yang lebih tinggi daripada ketika mereka menyimpannya dalam Rupiah.

Cara lain yang bisa dilakukan untuk mengantisipasi adanya inflasi adalah dengan mengalokasikan selisih penerimaan dengan pengeluaran atau keuntungan usaha dalam bentuk berinvestasi di sector riil agar dana yang terkumpul bisa berkembang.

\section{Pengertian Investasi}

Investasi menurut Muhamad adalah segala sesuatu yang bertujuan untuk mengembangkan harta yang dimiliki. Dalam investasi terkandung hubungan antara keuntungan yang diharapkan dan resiko yang dihadapi. Menurut Ahmad Gozali (dalam Muhamad), investasi penting dan perlu karena: 1. Fisik tidak selamanya sehat dan kuat untuk bekerja, 2. Hargaharga terus naik, 3. Dibutuhkan dana cadangan untuk mengantisipasi keadaan darurat, 4 . Generasi mendatang memiliki hak akan warisan. ${ }^{13}$

Prinsip-prinsip ekonomi islam dalam investasi antara lain adalah : 1. Tidak mencari rizki pada hal yang haram, baik dari segi zatnya maupun cara mendapatkannya, serta tidak menggunakannya untuk halhal yang haram, 2. Tidak mendzalimi dan tidak didzalimi, 3. Keadilan pendistribusian kemakmuran, 4. Transaksi dilakukan atas dasar ridha sama ridha, 5. Tidak ada unsur riba, maysir dan gharar. ${ }^{14}$

Adapun dalil yang bisa dijadikan sebagai landasan untuk berinvestasi adalah Al Qur'an Surah An Nisa (4:29) yang artinya:

"Wahai orang-orang yang beriman, janganlah kamu saling memakan harta sesamamu dengan jalan yang batil (tidak benar), kecuali dalam perdagangan yang berlaku atas dasar suka sama suka di antara kamu. Dan janganlah kamu membunuh dirimu. Sungguh, Allah Maha Penyayang kepadamu".

\footnotetext{
${ }^{13}$ Muhamad, Manajemen Keuangan Syariah, (Yogyakarta:UPP STIM YKPN, 2016). Cet ke-2, h. 431 - 436. ${ }^{14} \mathrm{ibid}$
} 


\section{Perjalanan Kembali kepada Dinar dan Dirham}

Bagi kita umat islam sebenarnya 14 abad yang lalu sudah diingatkan Allah untuk tidak mempercayakan urusan harta atau uang ini kepada negara seperti Amerika Serikat yang seharusnya tunduk pada kesepakatan Bretton Woods yang digagasnya sendiri, ternyata justru mereka mengingkarinya. ${ }^{15}$ Untuk itu coba kita perhatikan firman Allah dalam Al Qur'an sebagai berikut:

"Di antara Ahli Kitab ada orang yang jika kamu mempercayakan kepadanya harta yang banyak, dikembalikannya kepadamu, dan di antara mereka ada orang yang jika kamu mempercayakan kepadanya satu dinar, tidak dikembalikannya padamu, kecuali jika kamu selalu menagihnya. Yang demikian itu lantaran mereka mengatakan : Tidak ada dosa bagi kami terhadap orang-orang umi. Mereka berkata dusta terhadap Allah, padahal mereka mengetahui”. (QS. Ali Imran (3) : 75)

Dari data lebih dari satu setengah abad antara pertengahan abad 17 sampai awal abad 19, ketika islam dibawah Kekhalifahan Ustmaniah dan dunia barat diwakili oleh Inggris, ternyata Kekhalifahan Islam lebih bisa menjaga stabilitas harga dibandingkan dengan dunia barat. Dengan berpegang pada Dinar dan Dirham bukan berarti Islam tidak maju dalam bidang ekonomi dan perdagangan. Sebelum dunia barat menemukan cek, umat Islam sudah menggunakan Sakk, bahkan dari nama Sakk inilah istilah cek atau check atau cheque ditemukan. Kemudian ketika dunia barat belum menemukan letter of credit, menurut Dr. M. Umer Capra dunia Islam sudah menggunakan konsepnya secara luas yaitu yang disebut Hawala dan Suftaja. ${ }^{16}$

Penggunaan Dinar dan Dirham tidak harus berarti kembali ke zaman dahulu. Dengan teknologi modern Dinar dan Dirham dapat digunakan secara praktis dengan bantuan teknologi. Saat ini kita sudah bisa berbelanja dengan di dunia maya dengan menggunakan e-dinar misalnya lewat www.e-dinar.com. Teknologi bisa sama-sama modern, tetapi uang yang berbasis Dinar dan Dirham tetap sangat berbeda dengan uang kertas. Nilai Dinar dan Dirham benar-benar 100\% setara

\footnotetext{
${ }^{15}$ Ibid, Muhaimin Iqbal. h. 38.

${ }^{16}$ Ibid, Muhaimin Iqbal. h. 40.
} 
dengan nilai emas dan perak itu sendiri. Sementara nilai uang kertas lebih bersifat persepsi atau nilai yang dipaksakan. ${ }^{17}$

Oleh karena itu, sudah saatnya bagi bangsa Indonesia dan umat Islam untuk bersandar pada mata uang yang memiliki tingkat kestabilan yang lebih terjamin tanpa dipengaruhi oleh hukum permintaan dan penawaran uang, bebas dari inflasi, bunga (riba), gharar, gambling, dan unsur- unsur spekulatif. Umat Islam harus segera melepaskan rantai ketergantungan terhadap konsep nilai bunga. Maka pilihan yang paling tepat, yaitu "back to Dinar and Dirham", seperti telah digunakan sejak zaman Romawi hingga ambruknya Kekhalifahan Usmaniyah, $1924 .^{18}$

Kita sebagai bangsa yang merdeka telah memiliki pengalaman yang begitu pahit, bahwa karena kita tidak menggunakan mata uang yang benar-benar memiliki nilai intrinsik seperti Dinar dan Dirham, mata uang kita begitu mudah hancur dan dihancurkan. Dampak kehancuran mata uang ini tidak berhenti disini, yang paling menyedihkan adalah kita benar-benar bisa kehilangan kedaulatan atas negeri ini, minimal kedaulatan ekonomi. Masih segar diingatan kita, bagaimana pada tanggal 15 Januari 1998, Presiden Republik ini harus mengikuti kemauan IMF dengan menandatangani 50 butir kesepakatan. Di butir-butir tersebutlah Indonesia kehilangan kedaulatan ekonominya sejak 15 Januari 1998. ${ }^{19}$

Gagasan awal untuk kembali pada Dinar dan Dirham dilakukan pada suatu konferensi pada bulan Agustus 2002 dengan tema: "Stable and Just Global Monetary System" menghasilkan penerapan Dinar emas pada transaksi perdagangan luar negerinya dengan mitra dagang melalui Pengaturan Pembiayaan Bilateral (Billateral Payment Arrangement) atau BPA. Gagasan tersebut dilanjutkan pada seminar di Kuala Lumpur tanggal 22-23 Oktober 2002 dengan tema: "The Gold Dinar in Multilateral Trade" dengan menyetujui usulan Kepala Bank Sentral Iran, Bijan Latif untuk membentuk suatu sekretariat yang

\footnotetext{
${ }^{17}$ Ibid, Muhaimin Iqbal. h. 41,

${ }^{18}$ Muhamad Bahrul Ilmi, An Analysis of Feasibility of Dinar and Dirham as Currency Upon Transaction in Indonesian. (Seminar Nasional dan Call for Papers : FE UNISBANK, 2012) cet ke-1, h. 3.

${ }^{19}$ Ibid, Muhaiman Iqbal h. 31
} 
ditugasi mengkoordinir pengembangan kebijaksanaan Dinar islami (Perwaatmadja, 2003). Hasil Sidang ke-27 Dewan Gubernur Islamic Develpment Bank (IDB) tanggal 22-23 oktober 2002 di OuagadouguBurkin Faso, delegasi Malaysia dipimpin oleh Deputi Menteri keuangan Syafie Mohd Salleh telah mengajak negara anggota IDB, termasuk Indonesia menerima konsep perdagangan dengan mempergunakan Dinar emas untuk memfasilitasi dan meningkatkan perdagangan antar negara anggota dan mitra dagang lainnya. Dan konferensi di Kuala Lumpur tgl 2-3 november 2002, Indonesia telah menjadi salah satu negara pendiri the Islamic Financial Service Board (IFSB) bersamasama dengan Bahrain, Iran, Kuwait, Malaysia, Pakistan, Saudi Arabia, Sudan, Uni Emirat Arab dan Islamic Development Bank (IDB). Dalam konferensi ini antara lain dibahas penerapan penting dari Bank Sentral dalam penerapan Dinar emas pada penyelesaian Pembayaran Sistem perdagangan Bilateral dan Multilateral. ${ }^{20}$

Alasan mengapa Dinar \& Dirham dianggap sebagai alat investasi dan hedging yang aman dan menjanjikan, adalah adanya beberapa alasan dari penggunaan mata uang dinar Islam dalam menuju stabilitas sistem moneter, ${ }^{21}$ antara lain:

1. Uang yang stabil. Perbedaan uang dinar dengan uang fiat adalah kestabilan nilai uang tersebut. Setiap mata uang dinar mengandung 4.25 gram emas 22 karat dan tidak ada perbedaan ukuran emas yang dikandung dinar pada setiap negara, tidak ada perbedaan nilai dinar yang digunakan di Irak dengan dinar yang digunakan di negara Arab saudi. Uang dinar tidak mengalami inflasi semenjak zaman Rasulullah SAW hingga sekarang. Sebuah penelitian telah dilakukan oleh professor Roy Jastram dari Berkeley University dengan menulis buku tentang The Goldent Constant. Ia melakukan penelitian harga emas terhadap beberapa komoditi untuk waktu 400 tahun hingga 1976. hasil dari penelitiannya adalah bahwa harga emas adalah konstan dan stabil. Sekalipun selama waktu tersebut

\footnotetext{
${ }^{20}$ Darwis Harahap, Analisis Stabilitas Dinar Emas dan Dollar AS dalam Denominasi Rupiah, (Jakarta :Jurnal Al Iqtishad, UIN Syarif Hidayatullah vol vi no.2, 2014) cet. ke-1, h. 269.

${ }^{21}$ Maulana Angga W, Dinar dan Dirham dalam Perspektif Islam dikutip dari https://indonesiana.tempo.co, Kamis 29 Desember 2016 diakses 24 oktober 2018
} 
telah terjadi krisis, perang, dan bencana alam nilai emas relatif stabil (Vadillo, 2002).

2. Alat tukar yang tepat. Dengan adanya nilai yang stabil dan standar yang sama di setiap negara, dinar akan memberikan kemudahan dan kelebihan bagi masyarakat untuk melakukan transaksi domestik dan transaksi internasional sekalipun. Dinar adalah mata uang yang berlaku secara sendirinya, berbeda dengan fiat money sebagai legal tender yang membutuhkan pengesahan berupa hukum oleh pemerintah yang mencetaknya. Uang dinar emas adalah uang sudah dikenal selama berabad-abad, sehingga tidak diperlukan adanya proses penghalalan dan pengesahan sebagai uang.

3. Mengurangi spekulasi, manipulasi dan arbitrasi. Nilai dinar yang sama akan mengurangi tingkat spekulasi dan arbitrasi di pasar valuta asing, karena kemungkinan perbedaan nilai tukar akan sulit terjadi. Jika dinar sudah menjadi "single currency" yang sama di setiap negara, maka tidak akan ada perbedaan nilai dinar di setiap negara yang memberikan keuntungan yang besar kepada para spekulatorspekulator tersebut.

4. Karena setiap transaksi dinar dan dirham akan didasari oleh transaksi di sektor riil, maka penggunaannya dapat mengiliminir penurunan ekonomi atau economic downturn dan resesi.

5. Penggunaan dinar dan dirham dalam suatu negara akan mengiliminir risiko mata uang yang dihadapi oleh negara tersebut, apabila digunakan oleh beberapa negara yang berpenduduk Islamnya mayoritas akan mendorong terjadinya blok perdagangan Islam.

6. Penggunaan dinar dan dirham akan menciptakan sistem moneter yang adil yang berjalan secara harmonis dengan sektor riil. Sektor riil yang tumbuh bersamaan dengan perputaran uang dinar dan dirham, akan menjamin ketersediaan kebutuhan masyarakat pada harga yang terjangkau.

7. Berbagai masalah sosial seperti kemiskinan dan kesenjangan akan dengan sendirinya menurun atau bahkan menghilang. 
8. Kedaulatan negara akan terjaga melalui kesetabilan ekonomi yang tidak terganggu oleh krisis moneter atau krisis mata uang yang menjadi pintu masuknya kapitalis-kapitalis asing untuk menguasai perekonomian negara dan akhirnya juga menguasai politik keamanan sampai kedaulatan negara.

9. Hanya uang emas (dinar) dan perak (dirham) yang bisa menjalankan fungsi uang modern dengan sempurna yaitu fungsi alat tukar (medium of exchange), fungsi satuan pembukuan (unit of account) dan fungsi penyimpan nilai (store of value).

Alasan lain mengapa Dinar dan Dirham bisa dijadikan sebagai sarana investasi dan hedging yang aman dan menjanjikan adalah janji Allah SWT sebagai berikut :

Di antara persyaratannya antara lain, kaum muslimin harus kembali kepada ajaran agama Islam yang benar. Allah Azza wa Jalla berfirman dalam QS An Nur 55 yang artinya :

"Dan Allah telah berjanji kepada orang-orang yang beriman di antara kalian dan mengerjakan amal-amal yang saleh bahwa Dia sungguhsungguh akan menjadikan mereka berkuasa dimuka bumi, sebagaimana Dia telah menjadikan orang-orang sebelum mereka berkuasa, dan sungguh Dia akan meneguhkan bagi mereka agama yang telah diridhaiNya untuk mereka, dan Dia benar-benar akan menukar (keadaan) mereka, sesudah mereka dalam ketakutan menjadi aman sentosa. Mereka tetap menyembahku-Ku dengan tiada mempersekutukan sesuatu apapun dengan Aku." (QS. An-Nur: 55).

Sehingga ketika kaum muslimin kembali kepada ajaran Islam yang benar, janji kemakmuran itu akan datang. Insya Allah. Dan diantara parameter kemakmuran itu adalah berlakunya kembali mata uang Islam yaitu Dinar emas dan Dirham perak. ${ }^{22}$

Hal lain yang bisa dijadikan landasan bahwa Dinar dan Dirham memiliki superioritas adalah adanya penyebut secara implicit pada $\mathrm{Al}$

\footnotetext{
22 Ibid, Maulana Angga W.
} 
Qur'an dimana Allah menyebutkan kata emas dan perak dalam QS At Taubah :34) ${ }^{23}$ yang artinya :

"Wahai orang-orang yang beriman. Sesungguhnya banyak dari orangorang alim dan rahib-rahib mereka benar-benar memakan harta orang dengan jalan yang batil, dan mereka menghalang-halangi (manusia) dari jalan Allah. Dan orang-orang yang menyimpan emas dan perak dan tidak menginfakkannya di jalan Alah, maka berikanlah kabar gembira kepada mereka, (bahwa mereka akan mendapat) azab yang pedih". (QS At Taubah : 34)

\section{Hasil Penelitian yang Mendukung Dinar dan Dirham Memiliki Nilai yang Stabil}

Hasil penelitian yang mendukung apabila Dinar dan Dirham memiliki nilai yang stabil sehingga cocok dijadikan sebagai sarana investasi dan hedging yang aman dan menjanjikan adalah :

1. Berdasarkan pada hasil penelitian tentang Analisis Investasi Dinar (Studi pada Gerai Dinar) yang dilakukan oleh Anna Madania, expected return dinar dan expected return SWBI memiliki perbedaan yang sangat signifikan yaitu E( R) Dinar 1,66\% sedangkan E (R) SWBI sebesar 0,46\%. Hal ini membuktikan bahwa Dinar lebih baik dibandingkan dengan SWBI dari segi expected return. ${ }^{24}$

2. Sedangkan berdasarkan hasil penelitian tentang Analisis Komparasi Investasi Dinar dan Investasi Reksadana Pasar Uang Syariah dari Nur Ayu Eva Feriyani menjelaskan bahwa tidak ada perbedaan signifikan berinvestasi di Reksadana PUAS maupun Dinar, jika dilihat dari segi return, Reksadana PUAS lebih unggul dengan menunjukkan angka $2.74 \%$ sedangkan return Dinar hanya menunjukkan angka $1.56 \%$. Jadi return Reksadana PUAS lebih unggul sebesar $1.18 \%$ dari return Dinar. Meskipun dari segi

\footnotetext{
${ }^{23}$ Agustianto, Keunggulan dan Keberkahan Dinar, dikutip dari http://islamicfinance.co.id diakses tanggal 27 oktober 2014.

${ }^{24}$ Anna Madania, Analisis Investasi Dinar, (Skripsi Fakultas Syariah dan Hukum UIN Syarif Hidayatullah, 2009).
} 
return Reksadana PUAS lebih unggul tapi, dari segi risiko reksadana PUAS sangat tinggi yaitu 55,6\% sedangakan Dinar hanya memiliki risiko 5,75\%. Jika dibandingkan maka Reksadana PUAS dengan Dinar adalah 55,6\%: 5,75\% atau kurang lebih 1:9,7 maka, jika dilihat dari segi risiko Dinar lebih unggul dibandingkan Reksadana PUAS. $^{25}$

3. Berdasarkan dari penelitian tentang Analisis Stabilitas Dinar Emas dan Dollar AS dalam Denominasi Rupiah oleh Darwis Harahap, menjelaskan bahwa volatilitas harga Dolar AS dipengaruhi volatiltas Dinar emas dan volatilitas Dinar emas tidak dipengaruhi Dolar AS. Jadi Dinar emas lebih stabil dari pada Dolar AS. ${ }^{26}$

\section{Tata Cara Berinvestasi atau Melakukan Hedging dengan Dinar dan Dirham}

Di Indonesia saat ini Dinar dan Dirham hanya diproduksi oleh Logam Mulia - PT. Aneka Tambang Tbk. Hanya perusahaan tersebut yang secara teknologi dan penguasaan bahan mampu memproduksi Dinar dan Dirham dengan kadar dan berat sesuai dengan standar Dinar dan Dirham Rasulullah. Standar kadar dan berat ini pun tidak hanya di sertifikasi secara nasional oleh Komite Akreditasi Nasional (KAN), tetapi juga oleh lembaga sertifikasi logam mulia internasional yang sangat diakui yaitu London Bullion Market Association (LBMA) ${ }^{27}$

Perkembangan Dinar dan Dirham di Indonesia tidak lepas dari peran Gerai Dinar Indonesia dan Wakala Induk Nusantara. Pasalnya, dua lembaga ini memiliki beberapa produk dan event unggulan yang diselenggarakan secara nasional. Gerai Dinar Indonesia misalnya, melalui M-Dinar yang diprakarsai oleh Muhaimin Iqbal itu dapat diakses melalui internet dan mobile phone yang dapat dinikmati seluruh umat islam. Selain itu Wakala Induk Nusantara oleh Zaim Saidi

\footnotetext{
${ }_{25}$ Nur Ayu Eva Feriyani, Analisa Komparasi Investasi Dinar dan Reksadana Pasar Uang Syariah, (Jakarta:Jurnal Al Iqtishad UIN Syarif Hidayatullah vol. 5 no. 2, 2013) cet ke-1, h. 350.

${ }^{26}$ Darwis Harahap, Analisis Stabilitas Dinar Emas dan Dollar AS dalam Denominasi Rupiah, (Jakarta :Jurnal Al Iqtishad, UIN Syarif Hidayatullah vol vi no.2, 2014) cet. ke-1, h. 281.

27 Nur Azifah, Dinar Dirham dan Lintas Perkembangannya di Indonesia, dikutip dari http://zonaekis.com/Dinar Dirham dan Lintas Perkembangannya di Indonesia diakses 24 oktober 2018.
} 
memiliki 95 gerai tempat-tempat penukaran koin dinar dan dirham dari bank ke uang kertas. Melalui sosialisasi yang dilakukan oleh kedua pegiat Dinar Dirham tersebut maka Dinar Dirham telah cukup berkembang di Indonesia baik sebagai alat tukar, investasi, mahar maupun koleksi. Selain itu, kedua pegiat ini telah menetaskan banyak BMT dan koperasi serta outlet yang menjualbelikan dan menggunakan Dinar dan Dirham sebagai produk tabungan dan investasi sebagai upaya menghidupkan kembali sunnah Nabi yang telah lama hilang. ${ }^{28}$

Dengan semakin berkembangnya teknologi, melalui Gerai Dinar Indonesia saat ini bagi masyarakat muslim Indonesia yang ingin investasi ataupun hedging atas harta, bisa melakukannya dengan cara antara lain :29

1. Masyarakat bisa menggunakan internet untuk mengakses Tabungan M-Dinar.

2. Bagi yang tidak menggunakan internet bisa melalui tabungan fisik, dengan langsung datang ke kantor Koperasi BMT Daarul Muttaqiin di Jl. Kelapa Dua Raya 189 (d/h Jl. RTM). Kelapa Dua - TuguCimanggis - Depok 16951.

3. Melalui Koperasi/BMT yang sudah ada di lingkungan tempat tinggal/tempat kerja, syaratnya Koperasi/BMT tersebut menjalin kerjasama dengan Koperasi BMT Daarul Muttaqiin.

4. Melalui Koperasi/BMT baru yang didirikan di lingkungan tempat tinggal atau kantor Anda dengan bantuan atau kerjasama dengan Koperasi BMT Daarul Muttaqiin.

\footnotetext{
${ }^{28}$ Muhamad Zaki Yamani, Penetapan Transaksi Jual Beli Dinar dan Dirham, (Skripsi Fakultas Syariah dan Hukum, UIN Syarif Hidayatullah, 2015)

${ }^{29}$ Muhaimin Iqbal, "Menabung Dinar Menjadi Semakin Mudah Dengan M Dinar Saving Account" dikutip dari http://www.geraidinar.com/index.php/82-gd-articles/dinar-emas/281-menabungdinar-menjadisemakin-mudah-dengan-m-dinar-saving-account di akses Selasa, 23 Oktober 2018
} 


\section{Berinvestasi dengan Dinar dan Dirham melanggar Peraturankah ?}

Adanya Undang-Undang dari pemerintah Indonesia yang perlu diperhatikan berkaitan dengan investasi Dinar dan Dirham yaitu peraturan tentang larangan untuk menggunakan mata uang lain selain Rupiah untuk bertransaksi di Indonesia.

Undang-Undang tersebut adalah UU no 7 tahun $2011^{30}$ yang kemudian diatur lebih lanjut dalam surat edaran Bank Indonesia berupa Surat Edaran BI (SEBI) No.17/11/DKSP tanggal 1 Juni 2015, tentang Kewajiban Penggunaan Rupiah di Wilayah Negara Kesatuan Republik Indonesia.

Dalam surat edaran disebutkan terhitung tgl 1 juli 2015, BI akan melakukan pengawasan terhadap kegiatan transaksi di dalam negeri, baik transaksi langsung atau tunai maupun tidak langsung atau non tunai. Untuk pengawasan transaksi tunai, BI bekerjasama dengan penegak hukum melalui MoU antara BI dengan Kapolri. ${ }^{31}$

Terhadap pelanggaran transaksi tunai akan dikenakan sanksi pidana, yaitu kurungan maksimum 1 tahun dan denda maksimum Rp 200 juta. Sementara pelanggaran terhadap transaksi non tunai akan diterapkan sanksi administrasi berupa teguran tertulis, kemudian wajib membayar $1 \%$ dari nilai transaksi dan maksimum Rp 1 miliar, dan larangan penggunaan lalu lintas pembayaran. ${ }^{32}$

Menurut Zaim Saidi bahwa berinvestasi dengan Dinar dan Dirham tidak melanggar hukum apapun. Beliau mengatakan, dalam peraturan perundangan BI tersebut mengatakan tidak diperbolehkannya penggunaan mata uang lain seperti Dolar dan Yen. Sedangkan DinarDirham masuk ke dalam kategori perhiasan, maka prinsip transaksinya

\footnotetext{
${ }^{30}$ Undang Undang No. 7 Tahun 2011 tentang Mata Uang, Lembar Negara Republik Indonesia Tahun 2011 Nomor 64.

31 Ibid

${ }^{32}$ Dewi Rachmat Kusuma, Berani Transaksi Tak Pakai Rupiah, Hukumannya Denda Sampai Penjara dikutip dari https://finance.detik.com/moneter/d-2957037/berani-transaksi-tak-pakai-rupiah-hukumannya-dendasampai-penjara diakses tgl 21 oktober 2018.
} 
layaknya barter yang berdasarkan kesepakatan, sedangkan barter tidak melanggar undang-undang apapun. ${ }^{33}$

Koin Dinar dan Dirham adalah milik pribadi, berbeda dari uang kertas yang merupakan nota utang BI dan tidak pernah menjadi milik pemegangnya. Dinar dan Dirham merupakan bagian dari tradisi dan budaya bangsa Nusantara, karena selama ratusan tahun digunakan di berbagai kesultanan di Nusantara, mulai dari Aceh sampai Gowa. Dan, yang paling pokok, Dinar dan Dirham merupakan bagian dari ibadah (pembayaran zakat, mahar, mumalat). ${ }^{34}$

Jadi, pemakaian Dinar dan Dirham merupakan hak asasi, hak konstitusional dan hak legal rakyat. Undang-undang mata uang yang ditafsirkan untuk melarang pemilikan dan penggunaan Dinar dan Dirham, bertentangan dengan UUD, bertentangan dengan undangundang perbankan dan undang-udang tentang $\mathrm{BI}$, serta bertentangan dengan Al Quran dan Sunnah Rasul SAW. ${ }^{35}$

Menghambat pemakaian kembali Dinar dan Dinar juga hanya akan merugikan masyarakat dan bangsa secara keseluruhan. Keduanya adalah aset riil. Semakin banyak Dinar dan Dirham yang berada di tangan masyarakat semakin kokoh ekonomi rakyat dan bangsa ini. Sebagaimana terbukti dalam masa satu dasawarsa ini Dinar emas dan Dirham perak bebas inflasi, menstabilkan ekonomi keluarga, menurunkan harga-harga, serta meningkatkan kesejahteraan masyarakat. ${ }^{36}$

\section{Kesimpulan}

Dalam berinvestasi atau melakukan hedging atas harta yang dimiliki, seyogyanya umat islam harus tunduk dengan tujuan ekonomi syariah yang menginginkan kebahagiaan yang falah, yang berguna bagi

\footnotetext{
33 Muhammad Hafil, Penggunaan Dinar-Dirham Dinilai tak Langgar Aturan BI dikutip dari https:/www.republika.co.id/berita/jurnalisme-warga/wacana/13/07/22/ekonomi/syariahekonomi/16/12/18/oidpqp326 diakses tgl 31 oktober 2018

${ }^{34}$ Zaim Saidi, Perlindungan Hukum atas Penggunaan Dinar Dirham, February 23, 2016 dikutip dari https://zaimsaidi.com/perlindungan-hukum-atas-penggunaan-dinar-dirham/ diakses 31 oktober 2018

${ }^{35}$ Ibid

${ }^{36}$ Ibid
}

KORDINAT Vol. XVIII No. 1 April 2019 
kehidupan dunia dan akhirat. Salah satu cara berinvestasi dan hedging yang paling aman dan menjanjikan adalah kembali pada sunnah Nabi yang sudah lama ditinggalkan yaitu investasi pada Dinar dan Dirham. Dinar dan Dirham dipilih karena nilainya yang stabil dan tidak mengakibatkan adanya inflasi pada perekonomian negara yang menggunakannya.

Saat ini dengan berkembangnya kemajuan teknologi, cara berinvestasi dan hedging dengan menggunakan sarana investasi Dinar dan Dirham tidaklah sulit misalnya dengan internet, masyarakat sudah bisa melakukan kegiatan pembelian atau penjualan Dinar dan Dirham.

Adanya pemikiran bahwa investasi Dinar dan Dirham telah melanggar peraturan dari pemerintah yang melarang penggunaan mata uang asing selain Rupiah untuk kegiatan transaksi, baik transaksi langsung atau tunai maupun tidak langsung atau non tunai adalah sesuatu yang salah karena dengan berinvestasi dengan Dinar dan Dirham berarti kita telah menghidupkan kembali sunnah Nabi yang bisa membawa umat islam kepada semakin kokohnya ekonomi rakyat dan bangsa.

\section{Daftar Pustaka}

Suseno, Siti Astiyah, 2009, Inflasi, Jakarta: Pusat Pendidikan dan Studi Kebanksentralan (PPSK) Bank Indonesia

Muhaimin Iqbal, 2007, Mengembalikan Kemakmuran Islam dengan Dinar dan Dirham, Jakarta: Spiritual Learning Centre - Dinar Club

M. Nur Rianto Al Arif, 2015, Pengantar Ekonomi Syariah, Bandung: Pustaka Setia

N. Gregory Mankiw, Euston Quah, Peter Wilson, 2013, Pengantar Ekonomi Makro Edisi Asia, Jakarta: Salemba Empat

Muhamad, 2016, Manajemen Keuangan Syariah, Yogyakarta:UPP STIM YKPN, 2016 
Bareyn Mochaddin, 3 Investasi yang Paling Menguntungkan Mana Pilihan Anda. dalam https://finance.detik.com/perencanaankeuangan/d-3346340 diakses 22 Oktober 2018.

Surahman, 2016, Analisis Kekuatan Dinar dan Dirham Sebagai Mata Uang Anti Krisis, Banten: Jurnal Ekonomi dan Bisnis Islam IAIN Sultan Maulana Hasanuddin, vol.1 no.2

Ridho Cahyo Nugroho, 2016, Konsep Lindung Nilai (hedging) dalam Transaksi Keuangan Syariah, Malang: FEB Unbraw

Oni Sahroni, Hasanuddin, Cecep Maskanul Hakim, 2016, Instrumen Hedging dan Solusinya Menurut Syariah, Bengkulu: Jurnal Ekonomi dan Perbankan Syariah Al Intaj vol. 2 no. 2 FEBI IAIN Bengkulu

Muhamad Bahrul Ilmi, 2012, An Analysis of Feasibility of Dinar and Dirham as Currency Upon Transaction in Indonesian, Seminar Nasional dan Call for Papers : FE UNISBANK.

Darwis Harahap, 2014, Analisis Stabilitas Dinar Emas dan Dollar AS dalam Denominasi Rupiah, Jakarta: Jurnal Al Iqtishad, UIN Syarif Hidayatullah vol vi no.2

Maulana Angga W, Dinar \& Dirham dalam perspektif Islam, dalam https://indonesiana.tempo.co, Kamis 29 Desember 2016 diakses 24 oktober 2018

Agustianto, Keunggulan dan Keberkahan Dinar, dikutip dari http://islamicfinance.co.id diakses tanggal 27 oktober 2014.

Anna Madania, Analisis Investasi Dinar, (Skripsi Fakultas Syariah dan Hukum UIN Syarif Hidayatullah, 2009).

Nur Ayu Eva Feriyani, Analisa Komparasi Investasi Dinar dan Reksadana Pasar Uang Syariah, (Jakarta:Jurnal Al Iqtishad UIN Syarif Hidayatullah vol. 5 no. 2, 2013)

Nur Azifah, Dinar Dirham dan Lintas Perkembangannya di Indonesia, dikutip dari http://zonaekis.com/Dinar Dirham dan Lintas Perkembangannya di Indonesia diakses 24 oktober 2018.

Muhamad Zaki Yamani, Penetapan Transaksi Jual Beli Dinar dan Dirham, (Skripsi Fakultas Syariah dan Hukum, UIN Syarif Hidayatullah, 2015) 
Muhaimin Iqbal, "Menabung Dinar Menjadi Semakin Mudah Dengan M Dinar Saving Account" dikutip dari http://www.geraidinar.com/index.php/82-gdarticles/dinar-emas/281-menabung-dinar-menjadi-semakinmudah-dengan-m-dinar-saving-account di akses Selasa, 23 Oktober 2018

Undang Undang No. 7 Tahun 2011 tentang Mata Uang, Lembar Negara Republik Indonesia Tahun 2011 Nomor 64.

Dewi Rachmat Kusuma, Berani Transaksi Tak Pakai Rupiah, Hukumannya Denda Sampai Penjara dikutip dari https://finance.detik.com/moneter/d-2957037/beranitransaksi-tak-pakai-rupiah-hukumannya-denda-sampaipenjara diakses tgl 21 oktober 2018.

Muhammad Hafil, Penggunaan Dinar-Dirham dinilai tak Langgar Aturan BI dikutip dari https://www.republika.co.id/berita/jurnalismewarga/wacana/13/07/22/ekonomi/syariahekonomi/16/12/18/oidpqp326 diakses tgl 31 oktober 2018

Zaim Saidi, Perlindungan Hukum atas Penggunaan Dinar Dirham, February 23, 2016 dikutip dari https://zaimsaidi.com/perlindungan-hukum-ataspenggunaan-dinar-dirham/ diakses 31 oktober 2018 